The distribution of pain scores on the visual analogue scales is shown in the Figure. There was a highly significant difference between the values for the active cream and the placebo $(p<0.0005)$.

The results on the four point verbal response scale of venepuncture pain also showed that the active cream was significantly superior to placebo. (Fisher's exact test, $\mathrm{p}<0.01$ ) There was no difference between the two treatments with respect to ease of venepuncture.

Most parents and patients considered the use of the active cream worth while. Parents were able to apply the cream to a suitable vein at home without difficulty. There were several occasions when patients had to wait for the cream to take effect, but this inconvenience was considered to be offset by the advantage of less painful venepuncture. Eleven of the 15 children or their parents said they would like to continue using the active cream.

There were occasional skin reactions, consisting of pallor or redness, to both active cream and placebo. These were transient and clinically unimportant.

\section{Discussion}

The results of this study clearly indicate that an anaesthetic cream is an effective agent for alleviation of venepuncture pain. It is slightly inconvenient to use, but many children requiring regular venepuncture seem to be sufficiently motivated to accept this. Most children in this study elected to continue using the active cream for subsequent venepuncture.
The factors affecting absorption of local anaesthetic through intact skin have been studied by Evers, who found it necessary to use a thick layer of cream as emulsion droplets in contact with the skin readily became depleted of local anaesthetic. ${ }^{3}$ In the same study percutaneous absorption of lignocaine and prilocaine into the systemic circulation was found to be measurable but slight.

As in all local anaesthetic preparations it is necessary to consider the potential for hypersensitive reactions. There is an extensive clinical experience with lignocaine and prilocaine given by injection, and true allergic reactions are extremely rare. There is no reason to believe that these agents applied topically will behave differently.

We acknowledge the help of Astra Pharmaceuticals Ltd.

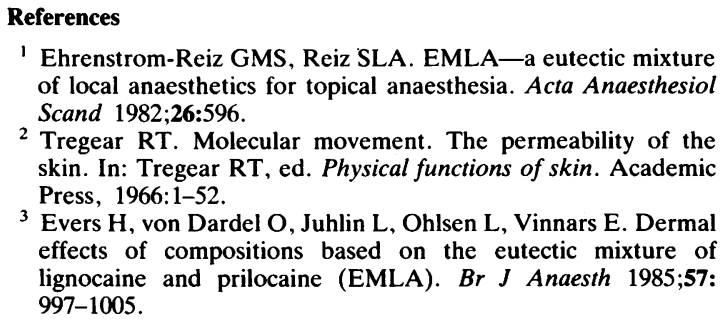

1 Ehrenstrom-Reiz GMS, Reiz SLA. EMLA-a eutectic mixture of local anaesthetics for topical anaesthesia. Acta Anaesthesiol Scand 1982;26:596.

2 Tregear RT. Molecular movement. The permeability of the skin. In: Tregear RT, ed. Physical functions of skin. Academic Press, 1966:1-52.

3 Evers H, von Dardel O, Juhlin L, Ohlsen L, Vinnars E. Dermal effects of compositions based on the eutectic mixture of lignocaine and prilocaine (EMLA). Br J Anaesth 1985;57: 997-1005.

Correspondence to Dr M Radford, Department of Child Health, Centre Block, Southampton General Hospital, Southampton SO9 $4 X Y$, England.

Received 30 June 1986.

\title{
Meningitis due to Haemophilus influenzae resistant to ampicillin and chloramphenicol
}

\author{
A P FRAISE, A C G MEEKS, AND J E RICHARDS \\ Department of Microbiology/Public Health Laboratory and Department of Child Health, \\ Leicester Royal Infirmary
}

SUMMARY A case of ampicillin and chloramphenicol resistant Haemophilus influenzae meningitis successfully treated with cefotaxime is described.

Meningitis due to Haemophilus influenzae resistant to chloramphenicol and ampicillin is a recognised problem in the United States ${ }^{1}$ but has only been reported once in the United Kingdom. ${ }^{2}$ To our knowledge the case reported here is the first British case to be treated with cefotaxime.

\section{Case report}

A previously healthy 7 month old boy presented in 
March 1986 with a one day history of lethargy, diarrhoea, and vomiting. On examination he was found to be febrile $\left(38^{\circ} \mathrm{C}\right)$ with pronounced neck and spinal rigidity. Initial investigation revealed a leucocytosis of $25000 \times 10^{6}$ cells $/ 1$ ( $83 \%$ polymorphs) and blood glucose concentration of $4.5 \mathrm{mmol} / \mathrm{l}(81$ $\mathrm{mg} / 100 \mathrm{ml}$ ). Cerebrospinal fluid (CSF) findings were as follows: white blood cell count $4800 \times 10^{6} / 1(85 \%$ polymorphs and $15 \%$ lymphocytes), red blood cell count $240 \times 10^{6} / 1$, protein: $>1.0 \mathrm{~g} / 1(100 \mathrm{mg} / 100$ $\mathrm{ml}$ ), glucose: $<1.0 \mathrm{mmol} / \mathrm{l}$. A Gram stain of the deposit showed pleomorphic Gram negative rods.

According to local practice treatment with chloramphenicol and penicillin was begun.

After overnight incubation $H$. influenzae, capsular type b, biotype 1 , was isolated from CSF and blood. The organism was subsequently found to be resistant to chloramphenicol and ampicillin but sensitive to cefotaxime and co-trimoxazole by comparative disc diffusion methods, using a local wild strain of $H$. influenzae as the control. Resistance to ampicillin was confirmed by showing production of $\beta$-lactamase, using a plate incorporation acidometric method (minimal inhibitory concentration being greater than $64 \mathrm{mg} / \mathrm{l}$ ).

The minimal inhibitory concentration to chloramphenicol was $16 \mathrm{mg} / \mathrm{l}$, and production of acetyl transferase activity was shown by the rapid method of Slack et al. ${ }^{3}$

Treatment was changed to cefotaxime $(150 \mathrm{mg} /$ $\mathrm{kg}$ /day in two divided doses). Repeat lumbar puncture after six days revealed a reduction in white blood cell count to $760 \times 10^{6} / 1$ (56\% polymorphs), a protein of $0.4 \mathrm{~g} / \mathrm{l}$, and a glucose of $2 \cdot 1 \mathrm{mmol} / \mathrm{l}$. CSF culture for bacteria yielded negative results. The CSF was bactericidal against the organism to a titre of 16 . The child made a slow but complete recovery with 10 days' treatment.

\section{Discussion}

$H$. influenzae type $\mathrm{b}$ resistant to ampicillin and chloramphenicol was first reported in Bangkok in 1979 as the cause of an outbreak of meningitis. ${ }^{4} \mathrm{~A}$ case of skin infection followed by respiratory infection reported in the UK in 1982 was subsequently found to be due to a non-capsule strain. ${ }^{5}$ The first British report of a capsulate strain causing meningitis was successfully treated with latamoxef and co-trimoxazole.

Multiply resistant $H$. influenzae is currently increasing in prevalence in the USA to the extent that extended range (third generation) cephalosporins have been considered in the first line treatment of childhood meningitis. ${ }^{6}$ Although the number of British reports is still small, any increase may force a similar review of our 'standard' treatment.

We thank the Public Health/Microbiology Laboratory at the John Radcliffe Hospital, Oxford, for their confirmation of the capsular typing and biotype of the isolate.

\section{References}

1 Hansman D, Forsyth K. Multiply resistant Haemophilus influenzac. Communicable Diseases Intelligence 1985;1:2-3.

2 Garvey RJP, McMullin GP. Meningitis due to beta lactamase producing type $\mathrm{b}$ Hacmophilus influenzae resistant to chloramphenicol. Br Med J 1983;287:1183-4.

3 Slack MPE, Wheldon DB, Turk DC. Rapid detection of chloramphenicol resistance in Haemophilus influenzae. Lancet 1977;ii:1366.

${ }^{4}$ Simasathien S, Duangmani C, Echeverria P. Haemophilus influenzae type $\mathrm{b}$ resistant to ampicillin and chloramphenicol in an orphanage in Thailand. Lancet 1980;ii:1214-7.

5 Sills JA, MacMahon P, Hall E, Fitzgerald T. Haemophilus influenzae type $\mathrm{b}$ resistant to chloramphenicol and ampicillin. Br Med J 1983;286:722.

${ }^{6}$ Chartrand SA, Marks MI, Scribner RK, et al. Moxalactam therapy of Haemophilus influenzae type $b$ meningitis in children. J Pediatr 1984:104:454-9.

Correspondence to Dr A P Fraise, Department of Microbiology/ Public Health Laboratory, Leicester Royal Infirmary, Leicester, England.

Received 9 July 1986 